\title{
El problema de las escalas en el campo de estudio de los exilios políticos argentinos recientes
}

\author{
The problem of scale in studies about \\ Argentine political recent exiles
}

\author{
Silvina Jensen \\ Universidad Nacional del Sur \\ Consejo Nacional de Investigaciones Científicas y Técnicas \\ (Argentina) \\ sjensen@criba.edu.ar
}

Soledad Lastra

Instituto de Altos Estudios Sociales/Universidad Nacional de La Plata

Consejo Nacional de Investigaciones Científicas y Técnicas

(Argentina)

lastra.soledad@gmail.com

\section{Resumen}

En la última década, el campo de estudio sobre los exilios políticos argentinos de los años setenta viene expandiéndose y diversificando su agenda de temas y problemas. Desde las investigaciones pioneras sobre trayectorias de intelectuales exiliados, memorias individuales de víctimas y reconstrucciones de comunidades nacionales del destierro, al mapa actual de pesquisas que profundizan dimensiones regionales, comparadas y transnacionales en el análisis de retornos, militancias humanitarias o lógicas represivas han pasado apenas unos años. Pero el territorio exiliar ha cambiado y lo ha hecho en no menor medida a partir de la puesta en juego de otras escalas temporales, espaciales y analíticas.

Este artículo se propone revisar diacrónicamente la producción acumulada en el campo de estudios sobre los exilios políticos argentinos de cara a elucidar las potencialidades y limitaciones de las diferentes escalas utilizadas. Partimos de la hipótesis que la actual apuesta por el diálogo de escalas está descubriendo puentes que conectan de forma más productiva la historia de los exilios políticos con la historia del pasado reciente de la Argentina. 
El trabajo se organiza en dos partes. La primera atiende a la problematización de la historiografía construida en escala nacional y biográfica y focalizada en la corta duración. La segunda, a las investigaciones sustentadas en la escala comparada, los estudios transnacionales y la reconstrucción de redes.

Palabras clave: Exilios políticos recientes - Historiografía - Argentina - Escalas

\begin{abstract}
Over the last decade, the studies about recent Argentine political exiles observes an expanding and diversifying agenda of issues and problems. Just a few years have passed from the research pioneer works (on trajectories of exiled intellectuals, on individual memories of victims and on the reconstruction of national communities in exile), to the current map of investigations that deepen all regional, comparative and transnational dimensions in the analysis of returns, humanitarian activism or repressive thinking. However, the territory of the exile studies has changed and it has done so, in no less measure, from other temporal, spatial and analytical scale brought into play.

This paper reviews the accumulated production in this field in order to elucidate the potential and limitations of the different scales used. Our starting assumption is that the current commitment to the dialogue between scales is discovering new bridges that may connect the history of the political exiles with the history of the recent past of the Argentina.

The work is organized in two main parts. The first part reviews the historiographical works based in both national and biographical scale. The second one focuses in the researches that deepen in a comparative, transnational and exile networks perspective.
\end{abstract}

Key Words Recent political exiles - Historiography - Argentina - Scales

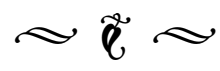

\section{Introducción}

La configuración en Argentina del campo de estudios sobre los exilios políticos de los años setenta resulta inescindible de la aparición de la Historia Reciente en sede académica y, a la vez, da cuenta de las zozobras y desafíos que la Historia Social -en sus vertientes analista, marxista-estructuralista y cuantitativa- viene transitando desde algo más de tres décadas, con profundos cuestionamientos a la cientificidad de la disciplina, su potencial explicativo, su estatuto narrativo y su capacidad para acceder a la verdad de lo ocurrido.

En este contexto, la cuestión de las escalas en la producción historiográfica acerca de los exilios políticos no resulta ajena a las mismas tensiones, apuestas y derivas que atraviesan tanto la práctica de la Historia Reciente en nuestro país, como la de las Ciencias Sociales y Humanas del campo intelectual occidental, 
a saber: la "antropologización del discurso histórico", ${ }^{1}$ el "retorno del sujeto", ${ }^{2}$ el "giro subjetivo", ${ }^{3}$ la "era del testigo", ${ }^{4}$ el imperio de las víctimas, ${ }^{5}$ el surgimiento de la Microhistoria italiana ${ }^{6}$ y el más pretérito cuestionamiento a una Historia prisionera en "compartimentos topográficos", 7 aquellos que Marc Bloch identificaba con el formato de la vieja Historia Político-Diplomática decimonónica, que recortaba sus objetos al interior de las fronteras administrativas de los Estados-nación.

Sin embargo, el problema de las escalas da cuenta, además, de cuestiones inscriptas en la naturaleza misma del exilio como experiencia y como proceso. Cabe señalar que si nos remontamos a la etimología del vocablo latino exsílium -derivado del verbo exsilire-, éste

1. DOSSE, François, La historia. Conceptos y escrituras, Nueva Visión, Buenos Aires, 2003, p. 63.

2. LE GOFF, Jacques, "Les retours dans l'historiographie française actuelle”, en BARROS, Carlos (editor) Historia de Debate: Otros enfoques, Santiago de Compostela, 1995, T. III, p. 163.

3. SARLO, Beatriz, Tiempo pasado: cultura de la memoria y giro subjetivo. Una discusión, Siglo XXI Editores, Buenos Aires, 2005.

4. Parafranseando a Annete Wierviorka, véase: WIERVIORKA, Annete, Lère du témoin, Plon, Paris, 1998.

5. TRAVERSO, Enzo, La historia como campo de batalla. Interpretar las violencias del siglo XX, Fondo de Cultura Económica, Buenos Aires, 2012, p. 295.

6. GINZBURG, Carlo, "Microhistoria: dos o tres cosas que sé de ella", en Entrepasados, Buenos Aires, 1995, Año 4, No 8, pp. 51-73; LEVI, Giovanni, "Sobre Microhistoria”, en BURKE, Peter (editor) Formas de hacer historia, Alianza Editorial, Madrid, 1999; SERNA, Justo y PONS, Anaclet, Cómo se escribe la microhistoria, Frónesis, Valencia, 2000.

7. BLOCH, Marc, "Pour une histoire comparée des sociétés européennes", en Revue de Synthèse Historique, París, 1928, T. XLVI, No 136-138, p. 44. habla de "saltar afuera de". De tal forma, el sentido más lato de la palabra exilio alude a un movimiento de salida de lo propio, fuera de sí mismo, del lugar natal, del espacio familiar y cotidiano, del territorio nacional. ${ }^{8} \mathrm{El}$ prefijo ex habla de una partida voluntaria sí, pero originada en una situación de persecución y violencia política o en una expulsión institucionalizada o no institucionalizada que, a lo largo de la historia, ha asumido la forma de remociones forzadas, destierros o deportaciones.

Pero cuando decimos exilio también referimos a un lugar, un territorio de refugio, de acogida, de protección donde salvaguardar la vida o la libertad. Un espacio otro, un nuevo Estado del que no se es nacional, ni ciudadano, al que no se pertenece y puede que con el que no se identifique, pero que da cobijo. De hecho, como explican Luis Roniger y Mario Sznajder, el formato temprano de los exilios en América Latina -aquel que los estructura hasta bien avanzado el siglo XX- se compone de tres elementos: el país expulsor, el país anfitrión $\mathrm{y}$ unos sujetos que huyen $\mathrm{o}$ son obligados a desplazarse por los poderes de turno. ${ }^{9}$

En tanto objeto poliédrico, el abordaje del exilio abre entonces la necesidad de combinar niveles y escalas de análisis múltiples y a la vez invita a no ser reacio a la interdisciplinariedad ${ }^{10}$

8. RAFFIN, Marcelo, "Exilio y potencia en la perspectiva agambeniana”, en BURELLO, Marcelo, LUDUEÑA ROMANDINI, Fabián y TAUB, Manuel (editores) Politicas del exilio. Orígenes y vigencia de un concepto, UNTREF, Buenos Aires, 2011, p. 60.

9. SZNAJDER, Mario y RONIGER, Luis , La politica del destierro y el exilio en América Latina, Fondo de Cultura Económica, México, 2013, p. 102.

10. RONIGER, Luis, "Reflexoes sobre o exílio como tema de investigaçao: avanços teóricos e desafios", en 
(Historia, Antropología, Sociología, Ciencia Política, Psicología, Estudios Culturales, Crítica Literaria, Cine, etc.). Porque si por una parte, resulta indispensable comprender a la vez el territorio que expulsa y que produce víctimas de un viaje no deseado originado en la violencia y la sociedad de destino -o sea ese espacio habitado por los perseguidos devenidos extranjeros-; en no menor medida, aprehender el objeto exiliar comporta interesarse por la experiencia de aquellos que viven entre un "aquí" y un "allá", dos geografías, pero también dos tiempos políticos, existenciales y simbólicos.

Esta dualidad fundante del exilio no se agota con el retorno al país de origen. En no pocos casos, el regreso lejos de anular el descentramiento vital, que condiciona la relación de los desplazados con el mundo y los lleva a definir "adentros" y "afueras" cambiantes, lo reedita y/o profundiza. Por otra parte, y al menos desde mediados del siglo XX, el territorio exiliar pasó a incluir un cuarto factor: la esfera pública internacional en la que los desterrados interactúan con "redes mundiales de solidaridad, organizaciones no gubernamentales y asociaciones internacionales", ${ }^{11}$ en orden a la promoción de sus intereses y de sus ideas y como parte del trabajo de cerco internacional de los regímenes autoritarios que forzaron/condicionaron sus salidas. Por último, debemos considerar que, desde las últimas décadas y con la movilidad de enormes contingentes de trabajadores

QUADRAT, Samantha Viz (organizadores) Caminhos Cruzados. História e memória dos exílios latino-americanos no século XX, Fundação Getulio Vargas Editora, Río de Janeiro, 2011, pp. 31-32.

11. RONIGER, Luis, Destierro y exilio en América Latina. Nuevos estudios y avances teóricos, Editorial Universitaria de Buenos Aires, Buenos Aires, 2014, p. 37. y refugiados de guerras civiles, tribales, catástrofes naturales o hambrunas en una sociedad cada vez más interconectada, ni siquiera resulta sencillo identificar el sentido de los flujos (salida-retorno), distinguir el tipo de migrante (permanente-temporario) o seguir pensando en polos invariables de ese desplazamiento (país expulsor/emisorreceptor/de refugio).

Nuestro presente de migraciones transnacionales ha abierto entonces un nuevo desafío a los investigadores de los exilios políticos masivos del siglo XX, invitándolos a cambiar la lente o a jugar en otro nivel de análisis que atienda a la constitución de solidaridades colectivas, redes intelectuales internacionales, configuraciones identitarias transfronterizas, trabajos multilocales en orden a la protección universal de derechos y a la elaboración de culturas políticas supranacionales. En esta coyuntura, aquellos que estamos interesados por los exilios políticos de la Doctrina de la Seguridad Nacional nos preguntamos por la pertinencia del uso de la escala transnacional en la indagación de procesos que sucedieron, strictu sensu, antes de que la arquitectura de la globalización gozara de sanción científica y social. $^{12}$

En este punto, cabe hacer una serie de señalamientos acerca de las escalas geográficas, temporales y analíticas en las que los historiadores leemos lo social. Por un lado, sostenemos que la elección de la escala forma parte de las decisiones teórico-metodológicas del investigador. Pero por otro, asumimos

12. Para un análisis de las continuidades y singularidades y/o rupturas de la nueva articulación de la sociedad mundo, véase SASSEN, Saskia, Territorio, autoridad y derechos. de los ensamblajes medievales a los ensamblajes globales, Katz, Buenos Aires, 2010. 
que no se trata de un juego arbitrario o de experimentación libre. Por el contrario, siguiendo las reflexiones de Bernard Lepetit afirmamos que esas escalas antes han sido vividas y moldeadas por el comportamiento de los actores sociales del pasado. ${ }^{13}$ Por lo tanto, reconociendo que la elección de una escala dada ni resulta neutra ${ }^{14}$, ni goza de una preferencia determinada de antemano, sostenemos que de lo que se trata es de ponderar cada escala por las configuraciones de lo social, las problemáticas del pasado o las causalidades de los fenómenos que nos ayuda a visibilizar.

Este artículo intenta analizar las potencialidades y limitaciones del uso (reflexivo o no reflexivo) de diferentes escalas en la producción historiográfica acerca del último exilio político argentino. No se trata de construir una Historia tribunal de segundo orden que examine la producción acumulada y la valore en virtud de su contribución o no a lo que consideramos "LA" escala legítima. Como dijimos, no existen escalas cuya pertinencia se pruebe en sí misma, sino que su oportunidad e importancia derivará de cuál es la pregunta del investigador, de qué tipo de fuentes dispone y de qué relaciones, tramas y lógicas sobre su objeto busca elucidar. Pero tampoco queremos limitar nuestro aporte a una enumeración o catálogo descriptivo de los heterogéneos niveles de análisis que pone de manifiesto la creciente producción sobre el exilio argentino de los setenta que incluye

13. LEPETIT, Bernard, "Sobre a escala na história”, en REVEL, Jacques (organizador) Jogos de escalas. $A$ experiência da microanálise, Fundaçao Getulio Vargas, Rio de Janeiro, 1998, p. 88.

14. REVEL, Jacques, "Microanálisis y construcción de lo social”, en REVEL, Jacques, Un momento historiográfico. Trece ensayos de historia social, Manantial, Buenos Aires, 2005, p. 44. entre otras, investigaciones sobre comunidades nacionales de destierro (México, Francia, España, etc.); grupos socio-profesionales (traductores, psicólogos y psicoanalistas, pedagogos, etc.); clases sociales (trabajadores), segmentos etarios (adolescentes y niños) y de género (mujeres) en el exilio; ideologías en la diáspora (socialismo, peronismo, maoísmo); biografías de grandes políticos y de intelectuales de renombre expatriados (Perón, Gelman, Bayer, Portantiero, Aricó); redes culturales y académicas del destierro y producción de ideas en tránsito (debates en torno a la democracia, la derrota, la violencia); representaciones y figuras del exilio y del destierro en la novela, el cine o la prensa; estudios comparados sobre políticas públicas de exilio y retorno o dinámicas transnacionales de lucha humanitaria.

En todo caso, nuestra propuesta apunta a valorar si algo tienen que ver las nuevas escalas -o la apuesta de los investigadores por una articulación más decidida entre diferentes escalas analíticas o espaciales en la interrogación del objeto exiliar- en el reforzamiento de los diálogos entre especialistas de los destierros y practicantes de la Historia Reciente en la Argentina.

Este trabajo se organiza en dos partes. En primer lugar, atiende a la problematización de la historiografía construida en escala nacional y biográfica y focalizada en la corta duración, $\mathrm{y}$, en segundo lugar, estudia las investigaciones sustentadas en la escala comparada, los estudios transnacionales y la reconstrucción de redes regionales. El artículo se cierra con algunas reflexiones que recuperan los principales clivajes de debate acerca del problema de las 
escalas en el campo de estudio de los exilios argentinos de los años setenta.

\section{Dimensiones biográficas, recuperación de experiencias y comunidades nacionales de destierro}

Si bien existe una primera producción acerca del exilio argentino contemporánea a la coyuntura de los retornos al país e impulsada sobre todo por sociólogos, demógrafos, psicólogos o especialistas en relaciones internacionales, ${ }^{15}$ y aunque desde mediados de los años noventa, antropólogos e historiadores desarrollaron otras investigaciones editadas en aquellos países que habían sido las principales geografías de la diáspora; ${ }^{16}$ la aparición de los

15. Sin pretender hacer un listado exhaustivo, cabe mencionar GRINBERG, Luis y GRINBERG, Rebecca, Psicoanálisis de la migración y del exilio, Alianza Editorial, Madrid, 1984; LATTES, Alfredo y OTEIZA, Enrique (coordinadores) Dinámica migratoria argentina (19551984): democratización y retorno de expatriados, Centro Editor de América Latina, Buenos Aires, 1987, 2 volúmenes; MALETTA, Héctor, "Del pasivo al activo: una política para los emigrados de América Latina”, en Estudios Migratorios, Centro de Estudios Migratorios Latinoamericanos, Buenos Aires, diciembre de 1988, Año 3, No 10, pp. 497-521; MALETTA, Héctor, SZWARCBERG, Frida y SCHNEIDER, Rosalía, "Exclusión y reencuentro: aspectos psicosociales del retorno de los exiliados a la Argentina", en Estudios Migratorios Latinoamericanos, Centro de Estudios Migratorios Latinoamericanos, Buenos Aires, agosto 1986, Año 1, No 3, pp. 293-321; MÁRMORA, Lelio y GURRIERI, Jorge, "El retorno en el Río de la Plata (las respuestas sociales frente al retorno en Argentina y Uruguay)", en Estudios Migratorios Latinoamericanos, Centro de Estudios Migratorios Latinoamericanos, Buenos Aires, diciembre de 1988, Año 3, No 10, pp. 467496.

16. Nos referimos a DEL OLMO PINTADO, Margarita, La construcción cultural de la identidad: emigrantes argentinos en España, Universidad Complutense, Madrid, 1990 [tesis doctoral] y La 102 primeros libros académicos en el mercado editorial argentino data del primer quinquenio del siglo XXI.

Buena parte de aquellas primeras producciones en clave antropológica o histórica revelan una fuerte impronta biográfica. Son investigaciones en las que la apelación a la primera persona -recuperando memorias a través de entrevistas personales, construyendo relatos de vida o reponiendo la audibilidad de un coro de voces desterradas- constituye no sólo un recurso analítico/metodológico/ expositivo y/o un posicionamiento específico frente al "giro subjetivo" de las Ciencias Sociales, sino también una apuesta éticopolítica en consonancia con el tono de las luchas por la memoria sobre el pasado dictatorial en la Argentina de los años ochenta y noventa y a la centralidad adquirida por el relato "traumático" de las "víctimas".

En esa línea, esta producción académica sobre el exilio argentino de los setenta oscila entre continuar el camino del boom testimonial (en clave periodística, fílmica, literaria, etc.), que desde tiempos de la dictadura en forma discreta y a lo largo de la década del ochenta de manera creciente, convocó a músicos, artistas, cineastas, novelistas, intelectuales y científicos reconocidos a reponer su experiencia del

utopía en el exilio, Consejo Superior de Investigaciones Científicas, Madrid, 2003; SÁENZ CARRETE, Erasmo, El exilio latinoamericano en Francia, 1964-1979, Potrerillos Editores, México, 1995; YANKELEVICH, Pablo (coordinador) En México, entre exilios. Una experiencia de sudamericanos, Plaza y Valdés Editores, México, 1998; JENSEN, Silvina, El exilio político argentino en Cataluña (1973-1983), Editorial Bosch, Barcelona, 1998 y MEYER, Eugenia y SALGADO MEYER, Eva, Un refugio en la memoria. La experiencia de los exilios latinoamericanos en México, Océano, México, 2002. 
destierro en primera persona, ${ }^{17}$ y avanzar en la reconstrucción histórica del peculiar tipo de proceso migratorio implicado por el último destierro. Se buscaba así proponer una Historia Sociocultural del Exilio desde la perspectiva del actor, desde la recuperación crítica de lo vivido y recordado, desde el rescate de la riqueza de perspectivas que aportaban aquellos hombres y mujeres concretos que protagonizaron la experiencia de la diáspora. Si el exilio no se contaba bajo la forma de una biografía o autobiografía, en cualquier caso, la Historia se explicaba apelando a todo tipo de egodocumentos, ${ }^{18}$ en especial, la producción de entrevistas como parte de esfuerzos particulares o institucionales que procuraban registrar, salvar del olvido o del silencio, la experiencia múltiple, cambiante y conflictiva de aquellos argentinos que salieron del país en los años setenta del siglo pasado.

Los principales libros de esta primera etapa comparten algunas marcas. En primer lugar, $\mathrm{y}$ aunque los investigadores no desconocían

17. De los múltiples relatos testimoniales que desde los años setenta circulan en el espacio público argentino, la primera obra coral es el libro de PARCERO, Daniel, HELFGOT, Marcelo y DULCE, Diego, La Argentina exiliada, Centro Editor de América Latina, Buenos Aires, 1985. En el prólogo, los autores señalan que no pretenden realizar un "análisis objetivo de los hechos", sino centrarse en las "vivencias intransferibles y personales" de cada exiliado.

18. "Hablar de exilio lleva implícita la figura del exiliado, categoría moldeada por la subjetividad, la ambigüedad y la contradicción. Ante los exilios registrados en un tiempo y un espacio precisos, surgen las fases subjetivas de los entes históricos. Entonces, estudiar cualquier éxodo implica comprender también al exiliado, tomar en cuenta dimensiones psicosociales y sociológicas. Ello permitirá entender mejor cómo ha sido vivida la experiencia, pese a las visiones parciales y limitadas", en MEYER, Eugenia y SALGADO, Eva, Un refugio en la memoria..., Op. Cit., p. 11. que la experiencia del exilio argentino fue “persecución”, “derrota”, "fractura”, “oposición antidictatorial" o "militancia", su interés original parecía estar más ligado a comprender los procesos de crisis, configuración y reconfiguración identitaria atravesados por los desterrados en tanto inmigrantes, con especial atención a la cotidianeidad desplazada y a la reconstrucción "de los puentes políticos, culturales y afectivos" con el país de destino. ${ }^{19}$

En segundo lugar, todos estas obras singularizaban la experiencia exiliar argentina de los años setenta, sea desde el rescate de trayectorias de destierro de personalidades de la cultura y la política; sea desde el relato de unos exilios anónimos, pero igualmente ajenos a la Historia Estructural, de agregados masivos o fundada en metodologías cuantitativas. La primera línea podría estar representada por En México, entre exilios. Una experiencia de sudamericanos, libro en el que Pablo Yankelevich solicitaba a Tununa Mercado (escritora), Sergio Schmucler (joven guionista y cineasta), Néstor García Canclini (antropólogo) y Marcelino Cerejeido (fisiólogo) que escribieran un texto "autorreferencial" que repusiera los "andamios" de su "experiencia del exilio", yuxtaponiendo "vivencias personales"y "reflexiones incisivas". ${ }^{20}$ La segunda, por Margarita del Olmo Pintado ${ }^{21}$ y su proyecto de una "antropología sin nativos" que evitara "cualquier generalización sobre la utopía o sobre el exilio para enfrentar al lector con cada una de las experiencias singulares y únicas" de "gente que quiso cambiar el mundo en la Argentina en la década de

19. Ídem, pp. 10-13.

20. YANKELEVICH, Pablo, En México, entre exilios..., Op. Cit., pp. 10-11.

21. DEL OLMO PINTADO, Margarita, La utopia del exilio..., Op. Cit. 
1970". ${ }^{22}$ Su libro La utopía en el exilio estaba organizado en tres partes ("En España", "Entre España y Argentina", "En Argentina") construidas en base a 18 relatos de exiliados argentinos que, leídos en conjunto, permitían entender, la "enorme complejidad" del mundo contemporáneo.

Por último, esta primera producción académica sobre el exilio argentino compartía una noción del exilio como fenómeno plural. Pablo Yankelevich afirmaba tempranamente que "no hay uno, sino múltiples exilios", recuperando la sentencia de María Luisa Tarrés. ${ }^{23}$ En 2007, con Silvina Jensen, Yankelevich confirmaba que el plural en la aproximación a los exilios es una "declaración de principios". ${ }^{24} \mathrm{El}$ énfasis en la dimensión individual de la Historia, el rescate de las experiencias y de las memorias y el acento en las formas plurales de atravesar el destierro representaban la escala pertinente para rescatar las voces represaliadas, silenciadas y descalificadas durante la última dictadura militar. Enfatizar que el exilio fue un proceso colectivo pero compuesto por miles de historias individuales -singularizadas por diferentes perfiles etarios, de clase, de género; por variables composiciones familiares; por diferentes patrones de residencia y desplazamiento; por disímiles derroteros políticos-militantes; por heterogéneas modalidades represivas sufridas antes de la salida y por distintos

22. Ídem, pp. 18-19.

23. YANKELEVICH, Pablo, En México, entre exilios..., Op. Cit., p. 12.

24. YANKELEVICH, Pablo y JENSEN, Silvina, "La actualidad del exilio", en YANKELEVICH, Pablo y JENSEN, Silvina (compiladores) Exilios. Destinos y experiencias bajo la dictadura militar, Libros del Zorzal, Buenos Aires, 2007, p. 15.

104 vínculos con la Argentina y con el país de expatriación-; permitía responder desde la investigación académica a aquellas imágenes simplistas y cristalizadas entre los extremos de la demonización castrense ("subversión en fuga", agente de la "campaña antiargentina") y la idealización surgida en el contexto de la temprana transición (víctimas, jóvenes idealistas, mártires, héroes).

Pero aquella apuesta fundacional por lo biográfico, ${ }^{25}$ por la construcción de testimonios

25. Cabe remarcar que siendo que lo testimonial ha sido una de las líneas estructurantes del campo historiográfico sobre el último exilio político argentino, strictu sensu no existen grandes biografías de exiliados. Por supuesto, no han faltado los apuntes o reconstrucciones biográficas, ni tampoco la reposición de contextos biográficos en el análisis de la vasta producción cultural e intelectual de los desterrados. En tal sentido, podríamos preguntarnos si esta ausencia -verificable si se la compara con la historiografía sobre el exilio republicano español y su apuesta por la elaboración de biografías no sólo de intelectuales y artistas, sino de sus políticos y sindicalistas- guarda relación con la composición del exilio argentino que, como sabemos, ni fue un movimiento organizado, ni tuvo instituciones de gobierno en el destierro, ni estuvo integrado mayoritariamente por la elite gobernante ni por los principales referentes de los partidos de la oposición parlamentaria. Asimismo, cabe puntualizar que en las biografías de los dirigentes de las organizaciones armadas, el tiempo de exilio suele ocupar (siguiendo una lógica que domina todas las biografías de "grandes hombres" de la política nacional: San Martín; Sarmiento, Perón) un lugar menor.

Con respecto a las biografías colectivas, pensamos en las investigaciones que aportan a la reconstrucción de biografías de grupos sociales y/o profesionales en el exilio (obreros, pedagogos y traductores) en el afán de analizar redes y debates intelectuales. Véanse entre otros BASUALDO, Victoria, "Una aproximación al exilio obrero y sindical”, en YANKELEVICH, Pablo y JENSEN, Silvina (compiladores) Exilios. Destinos y experiencias..., Op. Cit.; FALCON, Alejandrina, Exilio y Traducción. Importadores argentinos de literatura extranjera en España (1976-1983), Tesis doctoral inédita, Facultad de Filosofía y Letras, Universidad de Buenos Aires, 2014; y SUASNÁBAR, Claudio, Intelectuales, exilios y educación. 
orales y por la recuperación de la experiencia de los actores para la escritura de la Historia del último exilio político, expresaban en no menor medida la lógica del archivo disponible o, lo que es lo mismo, lo inexpugnable de los acervos estatales y aquellos que permiten tensar la mirada de los protagonistas del destierro con la lógica del Estado/los Estados (el de origen, pero también los de refugio o de tránsito) y sus múltiples agencias (Fuerzas Armadas y de Seguridad, Servicios de Inteligencia, Ministerios del Interior y Exterior, entre muchas otras).

Estos exilios múltiples, contados desde el recuerdo de sus protagonistas, tuvieron también una primera forma de interrogación ${ }^{26}$ ligada a la puesta en juego de la escala espacial nacional ${ }^{27}$ y/o nacional-estatal $y$ a la reconstrucción de un proceso no sólo delimitado por la duración temporal de las prácticas terroristas del Estado argentino, ${ }^{28}$

producción intelectual e innovaciones teóricas en educación durante la última dictadura, Prohistoria, Rosario, 2014.

26. Cabe señalar que el uso de la escala nacional no se ha abandonado y de hecho aún reclama la reconstrucción y/o profundización de otras geografías, sitios y metrópolis del exilio, por ejemplo: Alemania, Ecuador, Perú, Ginebra, Nueva York, etc.

27. En particular los trabajos de Jensen sobre Cataluña que más allá de no asumir las fronteras de un Estado, elige la reconstrucción de la "comunidad argentina" en una unidad política administrativa: Comunidad Autónoma de Cataluña, antes que dentro del espacio cultural de arraigo de la lengua catalana.

28. Con periodizaciones variables, la mayor parte de los trabajos tomaban el golpe del 24 de marzo de 1976 como punto de inflexión, aunque no como fractura absoluta y en tal sentido parecían atentos a esa "temporalidad fluida" que según Marina Franco, atraviesa el último gobierno peronista previo al golpe y el "Proceso de Reorganización Nacional”. FRANCO, Marina, Un enemigo para la nación. orden interno, violencia y "subversión", 1973-1976, Fondo de Cultura Económica, Buenos Aires, 2012, p. 18. sino recortado dentro de las fronteras políticoadministrativas del país de residencia de los desterrados.

La reconstrucción de capítulos nacionales (Francia, México, España, pero también Brasil, Suecia, Italia, Israel, Bélgica, Venezuela, Estados Unidos $)^{29}$ ha sido, sin ninguna duda, la columna vertebral de la consolidación del campo de estudios sobre el último exilio político argentino. ${ }^{30} \mathrm{El}$ uso de esta escala espacial ha resultado a veces de una reflexión crítica y funcional a las preguntas de investigación pero, en no menor medida, su preeminencia ha estado ligada a la legitimidad que gozaba en otras historiografías del exilio, por caso la del destierro republicano de la Guerra Civil Española que para los años noventa, acumulaba sólidas investigaciones sobre comunidades por países de residencia (Francia, México, URSS, Inglaterra, República Dominicana, entre otros), con especial atención a las interacciones

29. En buena medida, ésta fue la lógica de las compilaciones de YANKELEVICH, Pablo, Represión $y$ destierro. Itinerarios del exilio argentino, $\mathrm{Al}$ Margen, La Plata, 2004 y YANKELEVICH, Pablo y JENSEN, Silvina, Exilios. Destinos y experiencias...., Op. Cit.

30. Resulta importante destacar que el conjunto de trabajos publicados o inéditos sobre capítulos nacionales expresan tanto aproximaciones macro como microanalíticas y a veces una combinatoria de ambas. Algunos están escritos desde la perspectiva de los Estados receptores (los argentinos como refugiados, asilados) y otros desde la óptica de protagonistas del destierro. Algunos se inclinan por metodologías cuantitativas y apuestan por lecturas del exilio como un agregado, planteando algunas generalizaciones respecto a momentos de salida/radicación, composición socio-profesional en origen y destino, patrones de residencia y hasta impacto demográfico de las políticas de asilo y refugio. Sin embargo, la mayoría se apoya en herramientas cualitativas, recuperando subjetividades, experiencias, trayectorias, identidades y representaciones concretas y situadas dentro del marco nacional-estatal. 
políticas, sociales y culturales entre los recién llegados y el país anfitrión. ${ }^{31}$

Estos capítulos nacionales del último exilio argentino evidencian una especial atención a la reconstrucción de trayectorias, prácticas, identidades, procesos y representaciones localizadas en las capitales políticas o culturales de los Estados receptores. Esta deriva centralista (del centro político o cultural) expresa tanto una lógica consustancial a la historiografía política argentina $-y$, en no menor medida, de la Historia Recienteque se afirma "nacional", cuando en verdad proyecta "la realidad bonaerense" o "porteña" como explicación general válida para "otros espacios regionales o locales"; ${ }^{32}$ como la marca de una elección analítica, esto es, la apuesta de los exiliólogos por reconstruir el destierro desde la perspectiva de los emigrados más activos políticamente y los más visibles en la esfera pública del país de asilo que, en general, estuvieron radicados en capitales como México DF (Distrito Federal), París, Madrid o Roma. En algunos casos, esa reconstrucción de capítulos nacionales del exilio argentino surgió menos del interés por nuestra Historia Reciente que por la trayectoria de asilo y refugio de ciertos países. Quizás en esta línea el caso más emblemático sea el de México. ${ }^{33}$

31. Para analizar el estado del arte en torno al exilio republicano español, véase CABEZA SÁNCHEZALBORNOZ, Sonsoles, "Balance historiográfico del exilio español, 1990-1999", en Cuadernos de Historia Contemporánea, Madrid, 2000, № 22, pp. 135-157.

32. Sobre este tema, véase ÁGUILA, Gabriela, Dictadura, represión y sociedad en Rosario, 1976/1983. Un estudio sobre la represión y los comportamientos y actitudes sociales en dictadura, Prometeo Libros, Buenos Aires, 2008, pp. 20-23.

33. Como ejemplo, pueden verse los libros de YANKELEVICH, Pablo, México, país refugio..., Op. Cit.
Sin embargo, esta indagación sobre los denominados "sitios o lugares de exilio" 34 -esto es por aquellos Estados (México, Uruguay, Chile) y a veces ciudades (México DF, Caracas) que en periodos extensos y tanto en momentos tempranos como en tiempos recientes del pasado de Latinoamérica, operaron como lugares de acogida y encuentro de generaciones, corrientes y grupos de exiliados políticos-, también tiene mucho que ver con la lógica de expansión del campo académico de estudios sobre el último exilio argentino. De forma sintomática, todavía la historiografía no ha avanzado en la escritura de una Historia de la Argentina ni como país refugio, ni como productora de exilios en la larga duración. Esta laguna -asumible desde la puesta en diálogo con otras historiografías como la española que, sobre todo en las últimas décadas, se ha abocado a rescatar los éxodos políticos anteriores (moriscos, austracistas, jesuitas, afrancesados y liberales, carlistas, republicanos, monárquicos $\mathrm{y}$ derechas $)^{35}$ al destierro por antonomasia, el de la Guerra Civil de 1936-1939-; tiene hoy un referente ineludible en la obra ya citada de Mario Sznajder y Luis Roniger sobre el exilio como práctica de exclusión institucionalizada en la política latinoamericana durante los siglos XIX y XX.

Quisiera hacer dosúltimas puntualizaciones sobre el uso de la escala nacional. La

y MEYER, Eugenia y SALGADO, Eva, Un refugio en la memoria..., Op. Cit.

34. Sobre los lugares de exilio en América Latina en los siglos XIX y XX, véase SZNAJDER, Mario y RONIGER, Luis, La política del destierro..., Op. Cit., pp. 121-171.

35. Nos referimos entre otros a CANAL, Jordi (editor) Exilios. Los éxodos políticos en la Historia de España, siglos $X V$-XX, Sílex, Madrid, 2007. 
primera que la escala geográfica nacional ha contribuido muy especialmente a echar luz sobre la cotidianeidad de los argentinos como comunidad migrante de tipo específico que en los distintos países de residencia desplegó concretas interacciones políticas, económicas, laborales y culturales con la sociedad y el Estado anfitrión.

El peso de la localización del colectivo exiliado en el marco de un Estado-nación ha permitido responder tanto preguntas acerca de los procesos de reconfiguración identitaria resultantes de las relaciones habituales entre "recién llegados"y "dueños de casa", como sobre el trabajo político y de denuncia de los huidos de cara a su país de origen. En este último caso, no pocos trabajos sobre comunidades de argentinos exiliados en diferentes países de Europa o Latinoamérica reponen los diálogos entre huidos y actores políticos, sindicales, culturales y humanitarios de la sociedad de acogida; $y$, en no menor medida, reconstruyen la trama organizativa y las prácticas políticas específicas del colectivo exiliado en un ida y vuelta entre coyunturas calientes de la historia dictatorial argentina y las dinámicas propias del espacio público del país receptor.

La segunda consideración es que la escala nacional al visibilizar comunidades de exiliados por países de residencia, por un lado, si bien no impide, tampoco facilita pensar las interrelaciones que los argentinos desterrados tejieron en orden al diseño de estrategias políticas, humanitarias de lucha antidictatorial, de cooperación y solidaridad, más allá de los marcos estructurantes del Estado de residencia e involucrando actores en la esfera pública internacional y de las redes transnacionales. Por otro lado, explicar la historia de los argentinos exiliados en Cataluña, España, Venezuela o Italia puede introducir un efecto de sentido no deseado. Sabemos que la naturaleza de todo proceso exiliar es definir un "adentro" y un "afuera". Pero no desconocemos que los militares durante la última dictadura y otros actores de la sociedad civil en aquellos tiempos y aún después, han alimentado esa fractura entre una Argentina de "adentro" y una Argentina de "afuera", transformando lugares de residencias en identidades monolíticas, política y éticamente buenas o malas per se. En este punto, cabría preguntarse si la escala nacional es productiva o no para que el exilio como objeto de estudio deje de ser una excrecencia en la agenda de la Historia Reciente y que en cambio pueda escribirse sobre militancia, represión, movimiento de derechos humanos $\mathrm{o}$ actitudes y comportamientos sociales, en y con exilios.

\section{Los exilios en movimiento: espacios transnacionales, redes y la escala comparada}

De la mano de esos efectos de sentido que distancian a la Argentina de "adentro" de la de "afuera", los estudios más recientes que se están realizando desde otras escalas espaciales y temporales, vienen a tender puentes desde los cuales repensar la Historia Reciente argentina, pero también la Historia Reciente regional y sus relaciones con la migración política.

Como mencionamos en la introducción, Luis Roniger y Mario Sznajder señalan que la escala transnacional aparece como aquel espacio resultante de las acciones de denuncia de los exiliados latinoamericanos en el siglo $\mathrm{XX}$ a la vez que impulsor $\mathrm{y}$ amplificador de sus 
demandas y acciones. A la estructura tripartita que incluía en el análisis de los exilios a un Estado expulsor, una comunidad exiliada y un Estado receptor, se integra desde mediados del siglo XX la novedosa conformación de una cuarta variable que halla en lo transnacional la cualidad de convertir al exilio en un componente independiente con peso e influencias propios. ${ }^{36}$ Como explican estos autores, la arena global se integró como factor novedoso en la "ecuación del exilio" posibilitado por un lado, por las crecientes características transnacionales que fueron adquiriendo las fuerzas políticas revolucionarias en el Cono Sur -foco central de la lucha "antisubversiva" encarada por la Doctrina de Seguridad Nacional- y por el otro, por la fuerte coordinación represiva que fueron desplegando las Fuerzas Armadas $y$ de seguridad por fuera de las fronteras administrativas del Estado de origen. ${ }^{37}$ Así, la escala transnacional emerge como uno de los espacios característicos del accionar de los exilios masivos latinoamericanos desde mediados del siglo XX y, en consecuencia, como un elemento que reconfiguró las relaciones de los Estados-nacionales con los desterrados, y que hizo que expulsiones y destierros ya no fueran herramientas de exclusión operativas $y$ eficaces al momento de silenciar y anular políticamente al "otro".

36. SZNAJDER, Mario y RONIGER, Luis, La politica del destierro..., Op. Cit., pp. 181-183.

37. Esta fuerte vinculación entre la movilidad transnacional de los exiliados y la represión está siendo investigada por SLATMAN, Melisa y SERRA PADRÓS, Enrique, "Brasil y Argentina: modelos represivos y redes de coordinación durante el último ciclo de dictaduras del Cono Sur. Estudio en clave comparativa y transnacional", en JENSEN, Silvina y LASTRA, Soledad (editoras) Exilios: militancia y represión. Nuevas fuentes y nuevos abordajes de los destierros de la Argentina de los años setenta, Editorial de la Universidad Nacional de La Plata, La Plata, 2014.

108
La presencia y la urgencia por empezar a considerar la escala transnacional se fue haciendo evidente en los estudios sobre los exilios argentinos a través de las primeras investigaciones sistemáticas sobre los casos nacionales que recuperaban sobre todo la dimensión de la lucha humanitaria de los exiliados. Así, las investigaciones de Silvina Jensen y de Marina Franco sobre las prácticas de denuncia humanitaria situadas en casos nacionales, fueron iluminando hilos de redes de relaciones que mostraban no sólo cómo se fueron transformando las militancias políticas de muchos de estos actores -de los imaginarios "revolucionarios" a los "humanitarios"- sino que este pasaje en identidades y prácticas se había producido al compás del auge y crecimiento de una amplia red de organizaciones y entes gubernamentales y no gubernamentales que se vincularon con los exiliados integrándolos a repertorios de acción novedosos y de alcance internacional. Si las acciones de denuncia estaban dirigidas a condenar los crímenes estatales ocurridos en el país expulsor, esto se lograba a través de las tramas transnacionales de acción y difusión que amplificaban los contenidos de las demandas, articulando en ellas la situación del caso argentino con otros casos de violación a los derechos humanos de la región. ${ }^{38}$ En este sentido, es que Marina Franco advierte sobre la necesidad de revisar algunos de sus hallazgos obtenidos sobre el caso francés. Así explica que, si bien Francia habría operado como espacio de configuración y resonancia de las denuncias de los exiliados argentinos, no era menos cierto que determinados discursos y sentidos de la lucha francesa eran asimilables

38. Véase MARKARIAN, Vania, Idos y recién llegados. La izquierda revolucionaria uruguaya en el exilio y las redes transnacionales de derechos humanos (1967-1984), Uribe y Ferrari Editores, México, 2006. 
a lo ocurrido en otros casos nacionales, de manera que los contextos de los países de recepción podrían ser relativizados a la luz de futuras comparaciones y de profundizar en las redes transnacionales de denuncia para resituar el peso específico de cada variable. ${ }^{39}$

La escala transnacional involucra redes de relaciones entre exiliados de distintas nacionalidades $y$ actores que, sin formar parte del universo del destierro, tuvieron fuertes intervenciones en el mundo de los exilios y dieron forma a esas transformaciones políticas y discursivas mencionadas. Las redes transnacionales de defensa de los derechos humanos actuaron como canales para la participación y transformación política de muchos exiliados sudamericanos y fueron, sobre todo, vías para ejercer presión sobre los Estados de origen de los desterrados. ${ }^{40}$ Estos aspectos pueden reconocerse en investigaciones en curso sobre los exilios argentinos que, partiendo de preguntas diferentes, confluyen en la indagación sobre las dinámicas y morfologías que han asumido distintas redes de denuncia transnacional en la región. Uno de estos trabajos es el de Soledad Catoggio ${ }^{41}$ que muestra cómo los exiliados del Cono Sur hallaron en el mundo de la religión viejos puentes a través de los cuales circular la

39. FRANCO, Marina, Los emigrados politicos argentinos en Francia (1973-1983), Tesis doctoral inédita, Universidad de París 7, Francia, 2006, p. 635.

40. Sobre el desarrollo de las redes a nivel global, ver KECK, Margareth y SIKKINK, Kathryn, Activistas sin frontera: redes de defensa en politica internacional, Siglo XXI, México, 2000.

41. CATOGGIO, Soledad, "La trama religiosa de las redes humanitarias y del activismo transnacional en las dictaduras del Cono Sur de América Latina”, en JENSEN, Silvina y LASTRA, Soledad, (editoras) Exilios: militancia y represión..., Op. Cit. información sobre la desaparición forzada de personas y coordinar una acción conjunta de intercambios de prácticas y conocimientos que unieron a distintas organizaciones y personas vinculadas al mundo de los derechos humanos en países como Brasil, Uruguay, Argentina, y Chile. Por otra parte, también contamos con los primeros hallazgos obtenidos por Mario Ayala ${ }^{42}$ acerca del modo en que los exiliados argentinos residentes en Caracas fueron parte del proceso de configuración de una red regional humanitaria que culminó en la formación de lo que hoy conocemos como la Federación Latinoamericana de Asociaciones de Familiares de Detenidos Desaparecidos (FEDEFAM).

Las experiencias de activismo transnacional sobre las que se interrogan Ayala y Catoggio permiten descentrar al exilio argentino de los enfoques que sólo lo ven situado en su lugar de recepción, para perseguir los nudos de relaciones que llevaron a los emigrados políticos por fuera de esas fronteras político-administrativas y que los pusieron en estrecha vinculación con otras realidades latinoamericanas. Además, es interesante ver cómo estos trabajos revelan la confluencia de varios objetos de investigación. Así, Catoggio comienza su indagación sobre las redes religiosas y el activismo transnacional humanitario para "descubrir" a los exiliados como actores que en sus experiencias políticas produjeron un fortalecimiento de esas dinámicas reticulares. En cambio, Ayala parte del seno del campo de estudios de los exilios políticos desde el caso nacional de Venezuela y pasa a deshebrar toda una red de procesos e

42. AYALA, Mario, "Los exiliados argentinos en Venezuela. Solidaridad, denuncia y construcción de redes regionales de Derechos Humanos (1976-1981)", en JENSEN, Silvina y LASTRA, Soledad, (editoras) Exilios: militancia y represión..., Op. Cit. 
interacciones que van más allá de las fronteras nacionales y que integran a otros actores no necesariamente atravesados por la experiencia exilar pero sí por otras consecuencias de la represión estatal conosureña como la desaparición forzada de personas.

Además de estos sentidos de idas y vueltas entre los exiliados argentinos y otros exiliados latinoamericanos, las distancias entre el "adentro" y el "afuera" comienzan a desdibujarse cuando vemos cómo las nuevas preguntas que parten de la consideración sobre los espacios transnacionales muestran una fluida comunicación entre algunos exilios $y$ organizaciones de derechos humanos en un determinado país. Ayala por ejemplo muestra este vínculo, evidenciando cómo la FEDEFAM se constituyó a partir de la integración de organismos con sede en Argentina y gracias a la actuación de los opositores argentinos que estaban fuera del país. ${ }^{43}$ Así, un análisis sobre el transnacionalismo político, entendido como aquellas redes y actividades dirigidas desde afuera hacia la obtención de cambios en el país de origen, ${ }^{44}$ permite por un lado, identificar los lazos coordinados para la denuncia que se fueron tejiendo entre distintos actores argentinos societales e institucionales - tanto en el exilio como en el país - y, por el otro, reconocer en estas prácticas desterritorializadas la adopción por parte de los exiliados de distintas membresías

43. Una agenda que recupere las vinculaciones entre el "adentro" y el "afuera" del país debería incorporar además, la mirada sobre los intercambios e influencias que los exiliados argentinos tuvieron con los miembros de las estructuras partidarias del interior del país.

44. Sobre este concepto ver BAUBÖK, Rainer, "Hacia una teoría política del transnacionalismo migrante", 2003. Disponible en: <http://www.huellasmexicanas.org> [Consulta: 11 marzo 2015]. que - al calor de los intercambios con otros exilios latinoamericanos -, contribuyeron a transformar los repertorios de acción política. En consecuencia, lo transnacional recupera rasgos y cambios que la relación unilateral entre exiliados y Estados (expulsores o receptores) no explica en forma cabal.

Junto a la escala transnacional, vamos a detenernos ahora en los estudios comparados de los exilios. Marc Bloch había anunciado la importancia de la comparación para la Historia, indicando que esta disciplina "no puede alcanzar su meta más que superando la descripción de situaciones particulares para identificar, entre ellas, semejanzas y diferencias, convergencias y divergencias, relaciones y regularidades". ${ }^{45}$ Así, para Bloch, las comparaciones se podían realizar entre objetos lejanos o cercanos, es decir, entre sociedades que estuvieran separadas en tiempo $\mathrm{y}$ espacios o bien, entre procesos sociales que fueran contemporáneos y próximos desde el punto de vista geográfico. Sin embargo, uno de los principales temores que enfrentan los investigadores ante este enfoque tiene que ver con la posibilidad de alejarse de la especificidad de la Historia, con "perder" lo "humano" para priorizar escalas macro susceptibles de comparación que terminarían ofreciendo explicaciones sustentadas en variables rígidas o que redundarían en saltos cualitativos para generalizar regularidades. ${ }^{46}$ Así, el enfoque comparado se encuentra estigmatizado -o como mínimo resulta objeto de desconfianzaentre los historiadores porque en su apuesta

45. BLOCH, Marc, "Pour une histoire...", Op. Cit.

46. KRAUSS, Heidi Rositha, "Despedida de la Torre de Marfil. Historia comparada. Una introducción”, en Espacio, Tiempo y Forma, UNED, España, 2008, Serie III, T. XXI. 
por construir modelos teóricos o matrices conceptuales generales, pueden contribuir a reducir la complejidad de los procesos puestos en diálogo. Para los estudios sobre el exilio argentino, adscribimos a la propuesta de Luciano Alonso de desprender de los análisis algunas categorías unificadoras que alumbren los distintos casos; y de avanzar en una comparación que ayude a desnaturalizar las categorías utilizadas para nombrar en distintas experiencias algunos aspectos que aparentan ser iguales pero que en realidad son diferentes. ${ }^{47}$ En ese sentido, un estudio comparado sobre los exilios políticos debe enfocarse en la construcción crítica de un diálogo constante y fluido entre los casos comparables, en un ida y vuelta permanente que nos permita ver cómo determinados rasgos presentes de un modo en un caso, se encuentran o no en el otro, y arriesgar algunas reflexiones situadas en los contextos específicos que expliquen estas similitudes o diferencias.

A pesar de las críticas, la Historia Comparada comienza a ser lentamente valorada en el campo de estudios de los exilios como un enfoque que potencia la recuperación de la complejidad de estos procesos de migración política. ${ }^{48}$ Una de las primeras comparaciones es la desarrollada por Silvina Jensen, que toma dos procesos exilares masivos,

47. Véase el trabajo de Alonso sobre los regímenes represivos iberoamericanos del siglo XX, en el que compara categorías y variables analíticas para "extraer" marcos interpretativos y teóricos generales sobre prácticas $\mathrm{y}$ funciones de las violencias estatales. ALONSO, Luciano, "Modo de dominación y regímenes de violencia en las dictaduras iberoamericanas. Un esbozo de comparación”, en Revista e-l@tina, 2 0, 2007. Disponible en: < http://www.iigg.fsoc.uba.ar/elatina.htm> [Consulta: 10 marzo 2013].

48. RONIGER, Luis, Destierro y exilio en América Latina..., Op. Cit., p. 36. el exilio español y el argentino, en clave de dos sociedades alejadas en tiempo y espacio. Este recurso permite "descubrir nuevas claves de inteligibilidad que permanecen solapadas en lecturas reducidas al marco nacional-estatal" 49 y alumbrar algunas explicaciones sobre cada exilio, mostrando cómo a partir de algunos datos "duros" del exilio español en relación al argentino se pueden desprender especificidades de cada caso. Pero también, Jensen reconoce en estos análisis comparados los riesgos de caer en anacronismos y de potenciar falsas homologías si no hay una constante revisión de las operaciones que el investigador realiza para que dos procesos puedan ser comparados. $\mathrm{Si}$ una de las potencialidades de la comparación consiste en recuperar lo específico de un caso, también evitaría que postulemos "excepcionalidades nacionales" o "lecturas fatalistas” en la reconstrucción histórica.

Otro estudio comparado es el que desarrolla Soledad Lastra sobre las respuestas y políticas de recepción y asistencia a los retornados del exilio político en Argentina y en Uruguay durante las transiciones democráticas; es decir, a diferencia de Jensen, se trata de dos sociedades cercanas geográficamente y que son además contemporáneas. Producto de su tesis doctoral, la investigación toma en clave de una Historia Comparada aquellos sentidos, problemas y conflictos que aparecen en ambos casos nacionales para deshilar a partir de ellos las variables que explican que algunos de esos sentidos y políticas sobre el retorno hayan sido compartidos y otros no. Este trabajo evidencia

49. JENSEN, Silvina, "Agendas para una historia comparada de los exilios masivos del siglo XX. Los casos de España y Argentina”, en Pacarina del Sur. Revista de Pensamiento Crítico Latinoamericano, 2011. Disponible en: <http://www.pacarinadelsur.com/dossiers/dossier-1> [Consulta: 20 abril 2014]. 
que los desafíos ante el "reduccionismo" de la escala comparada son importantes y que, si bien la comparación puede alumbrar especificidades también puede llevarnos a una doble "trampa": las falsas similitudes y las falsas causas locales. ${ }^{50}$ Por ejemplo, en relación a las "falsas similitudes", Lastra muestra cómo las organizaciones sociales que dieron atención a los retornados en Argentina y en Uruguay tuvieron un punto de partida en "común" porque en ambos casos operaron enraizadas en la sociedad civil mientras que, a la vez, esto requirió de un ejercicio de indagación aparte sobre los lazos que estas organizaciones tenían con distintos actores de los sistemas políticos o de los organismos de derechos humanos en cada país, para mostrar cómo una imagen "coincidente" podían explicarse por orígenes diferentes (algunos con fuertes intervenciones por parte de los partidos políticos y otros con notorias ausencias de esos actores)..$^{51}$ Por otro lado, en relación a las "falsas causas locales", esta investigación descubrió puentes y conexiones entre los casos que se querían comparar: específicamente se trataba de algunos aspectos que las organizaciones uruguayas -sociales y estatales- habrían "aprendido" de las argentinas. De manera que el desafío de la comparación se traducía aquí en no desestimar esos aprendizajes, sino en

50. AYMARD, Maurice, “¿Qué historia comparada, hoy?”, en BONAUDO, Marta, REGUERA, Andrea y ZEBERIO, Blanca (coordinadoras) Las escalas de la historia comparada. Dinámicas sociales poderes políticos y sistemas jurídicos, Miño Davila, Buenos Aires, 2008, T.I.

51. Véase LASTRA, Soledad, "Semillas de la recepción a los retornados del exilio argentino y uruguayo (19831985)", en Revista Cantareira, Dossier Os Legados as ditaduras civis-militares, Universidade Federal Fluminense, Brasil, 2014, No 20, pp. 71-90. Disponible en: <http://www.historia.uff.br/cantareira/v3/?p=1315> [Consulta: 20 abril de 2014]. mostrarlos y analizarlos pero, sin otorgarles un peso unilateral, como si todas las prácticas de asistencia se explicaran por esos vínculos. En este sentido, es importante analizar si aquello que comparamos no responde a procesos que están estrechamente relacionados entre sí, de manera que dos resultados que pueden parecer similares son en realidad producto de intercambios y relaciones entre recortes de análisis sobre los que operamos como si estuviesen separados.

En este punto podemos detenernos sobre una escala más dentro de estos incipientes enfoques del campo de estudios: el enfoque centrado en las redes regionales, en las conexiones y efectos de "espejo" entre dos o más casos. Para el análisis mencionado sobre las respuestas ante los retornos en Argentina y Uruguay, las sospecha se generaban a partir de las similitudes y de ciertos aires de familia entre los procedimientos y mecanismos para llevar adelante los programas de retorno en cada país, aspectos que, como adelantamos, respondían a una red de influencias e intercambios de conocimientos sobre este proceso migratorio que se había producido entre algunas figuras de Argentina nucleadas en el Centro de Estudios Legales y Sociales con otras organizaciones uruguayas de distinta naturaleza (estatales y del movimiento de derechos humanos). Con similares sospechas pero a partir de otros casos y de otra escala temporal, Silvina Jensen analiza en otro de sus trabajos, los vínculos de las comunidades étnicas catalanas de Argentina y Chile, en sus funciones de solidaridad con los exilios españoles a ambos lados de la cordillera desde finales de los años treinta y en el tránsito desde la Guerra Civil Española al final de la Segunda Guerra Mundial. La porosidad de la frontera 
chileno-argentina queda en evidencia a través de la exhibición de las redes regionales de solidaridad que se desplegaron desde distintos ámbitos -personales, familiares, institucionales, políticos, entre otros- coordinados para recibir a los españoles exiliados, enviar ayudas al viejo continente y articular campañas de denuncias del régimen franquista. Esto permite tensar las interpretaciones historiográficas del exilio español que, hasta la fecha, analizaban las respuestas societales como experiencias aisladas y fijadas por las fronteras de cada Estado-nación, sin profundizar en las distintas escalas -no sólo regionales, sino también inter $\mathrm{y}$ transnacionales- que las constituyeron. ${ }^{52}$

La pregunta por lo transnacional y por la dinámica de redes no hace otra cosa que recuperar dimensiones específicas en las que se desplazaron y actuaron los actores exílicos en el pasado, devolviéndoles la movilidad inherente a este tipo de migraciones. Así, no sólo se trata de recuperar dinámicas que acercaron a los actores en tiempo y espacio, sino de mostrar cómo ellas pueden explicarse por procesos de intercambio y circulación de ideas, sentidos, proyectos y problemas compartidos en un tiempo particular. ${ }^{53} \mathrm{El}$

52. JENSEN, Silvina, “Nacional/regional/transnacional: la diáspora catalana y el universo de la ayuda humanitaria desde la Guerra Civil española al final de la Segunda Guerra Mundial", en Trabajo y Comunicaciones, Revista del Departamento de Historia, Segunda Época, La Plata, 2015, No 40. Disponible en: <http://www. trabajosycomunicaciones.fahce.unlp.edu.ar> [Consulta: 15 marzo 2015]. También puede verse CORAZA DE LOS SANTOS, Enrique, "Redes: España y Uruguay, espacios de exilios”, en DUTRÉNIT BIELOUS, Silvia, ALLIER MONTAÑO, Eugenia y CORAZA DE LOS SANTOS, Enrique, Tiempos de exilios. Memoria e historia de españoles y uruguayos, Textual, Montevideo, 2008.

53. Por ejemplo, sobre los exilios del aprismo en el Cono Sur, Leandro Sessa identifica al aprista exiliado análisis de redes establecidas a nivel regional permite descentralizar las explicaciones de algunas características de los exilios como si respondiesen a una localización fija, para profundizar en la movilidad espacial y temporal de los contactos y conocimientos que pusieron en juego. Como dijimos, esta mirada aún no ha sido explorada en profundidad en los análisis específicos sobre el exilio argentino de los setenta, pero sí comienza a mostrar su potencial explicativo a través de otros estudios. $^{54}$

Unas últimas consideraciones sobre estas tres escalas merecen subrayar desafíos para el investigador. Uno es que desde lo transnacional y la perspectiva de redes, se incorporan nuevos actores y experiencias de exiliados argentinos que no tuvieron protagonismo público ni académico en los primeros tiempos de constitución del campo. En ese sentido, es notorio cómo se va alejando la atención sobre las figuras públicas o más reconocidas de los exilios intelectuales argentinos, para preguntarse por otros actores con intervenciones que, tras bambalinas, marcaron dinámicas y repertorios de acción

con la figura del "traductor" de ideas, para mostrar cómo las redes no sólo significaron la movilidad de las ideas por fuera de las fronteras nacionales sino también la reflexividad de los actores sobre su propia práctica política. SESSA, Leandro, "Los exiliados como 'traductores'. Las redes del exilio aprista en la Argentina en la década de los treinta”, en Trabajo y Comunicaciones, Revista del Departamento de Historia, Segunda Época, La Plata, 2015, No 40. Disponible en: <http://www. trabajosycomunicaciones.fahce.unlp.edu.ar/> [Consulta: 15 marzo 2015].

54. En este sentido, la perspectiva de redes para el estudio de los exilios políticos argentinos se nutre de una doble vertiente temática sobre el pasado reciente: los estudios sobre los organismos de derechos humanos y los que tratan de dilucidar las dinámicas de las redes desplegadas por la represión en la región. 
a nivel transnacional y regional. Esto puede significar una potencialidad -por la apertura del campo a nuevas trayectorias de exilios-, aunque no descartamos efectos no deseados, ya que o bien podrían marginarse algunos actores exílicos en detrimento de otros, o bien sobredimensionarse las dinámicas de lucha humanitaria de los exilios dejando por fuera otras dimensiones que también fueron constitutivas de las experiencias particulares de cada actor. Acometer investigaciones en clave transnacional y de redes obligará además a ampliar y profundizar en las fuentes documentales capaces de guiar al investigador sobre itinerarios geográficos y movilidades hasta ahora impensadas.

Sobre lo comparado, debemos subrayar que los resultados pecan de un carácter relativo, es decir, que arrojan interpretaciones que necesariamente han sido construidas a partir de la comparación, del diálogo y del enfrentamiento de los casos elegidos, de manera que los hallazgos no deberían ser iguales si se tomaran los casos de forma aislada. Aquí los efectos no sólo tienen que ver con las preguntas que vuelven comparables dos o más casos sino con lograr el equilibrio de lo específico y lo general, reponiendo contextos y temporalidades para fortalecer las interpretaciones. Además, si bien la comparación contribuye a dilucidar lo general de lo específico, su mismo desarrollo parece requerir de cierta acumulación previa de conocimientos para contrastar distintos casos de exilios, lo cual significa que es deseable que se realicen más y mejores investigaciones con equipos interdisciplinarios distribuidos regionalmente, capaces de intercambiar conocimientos y potenciar preguntas sobre otros casos nacionales.

\section{Consideraciones finales}

Este artículo propuso explorar diacrónicamente los límites y posibilidades de las distintas escalas analíticas puestas en juego por los investigadores del campo de estudios del exilio argentino de los setenta. Una mirada retrospectiva evidencia una fuerte impronta biográfica y un encuadre estadocéntrico en el origen del campo, que sólo en el último quinquenio comienza a tensarse a partir de la incorporación de nuevos enfoques que recuperan la interconexión, movilidad, flexibilidad y porosidad de los procesos de emigración política en la Historia Reciente argentina y con ello -y aún tímidamenteintroducen la necesidad de pensar también desde lógicas transnacionales, regionales y comparadas.

Estos giros en los focos de atención geográficos y temporales sobre las experiencias del exilio están en estrecha relación con las nuevas preguntas que comienzan a formularse sobre esta experiencia política. No se trata de que las escalas transnacional, comparada y las redes sean la panacea. Es sólo que permiten echar luz sobre otras dinámicas, prácticas y explicaciones que quedaban oscurecidas desde la reconstrucción egocéntrica y anclada en los compartimentos estatales. Pero, por supuesto en sus peculiares derroteros contribuyen a la profundización de algunos aspectos $\mathrm{y}$ al oscurecimiento de otros.

Como mencionamos, los cambios de objeto y las variaciones de escalas en el campo de estudios de los exilios políticos se inscriben y explican también a partir 
de una mayor relación analítica que se va entretejiendo entre el exilio como problema de investigación y las preguntas que atraviesan al campo de la Historia Reciente Argentina. Por mencionar un ejemplo, es notorio cómo desde hace algunos años, los historiadores de la militancia política y de la represión política estatal también comenzaron a apostar por una historia descentrada de las fronteras administrativas estatales para recuperar las claves regionales que moldean a sus objetos de estudio. ${ }^{55}$ Lo comparado también aparece en la marea de los temas pendientes de los investigadores argentinos del pasado reciente $\mathrm{y}$ se fortalece con nuevos trabajos editoriales $\mathrm{y}$ con la formación de equipos de investigación que lentamente comienzan a esbozar algunos ejes posibles de contraste entre las dictaduras del Cono Sur y de otros procesos represivos de la historia contemporánea. ${ }^{56}$

Estimulados por estos derroteros, los investigadores del exilio argentino trabajamos por asumir las escalas como problema, apostamos por abordajes complejos inscriptos en el juego de escalas y avanzamos a paso firme en la utilización de enfoques analíticos todavía poco explorados. En definitiva, desde lo biográfico hasta lo transnacional, desde lo micro a lo macro, los investigadores de los exilios argentinos estamos hoy encarando no sólo una ampliación de temas en un diálogo productivo con la Historia Reciente, sino

55.Ver BOHOSLAVSKY, Ernesto, FRANCO, Marina, IGLESIAS, Mariana y LVOVICH, Daniel, Problemas de historia reciente del Cono Sur, Prometeo-Universidad Nacional de General Sarmiento, Buenos Aires, 2010, V. I y II.

56. Ver por ejemplo, ÁGUILA, Gabriela y ALONSO, Luciano, Procesos represivos y actitudes sociales. Entre la España franquista y las dictaduras del Cono Sur, Prometeo, Buenos Aires, 2013. que con ellos enfrentamos nuevos desafíos analíticos, entre los que el problema de las escalas ocupa un lugar de no poca significación.

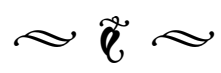

Recibido: $22 / 03 / 2015$

Aceptado: 16/06/2015

Publicado: 31/07/2015 